Türkiye Tarımsal Araştırmalar Dergisi
http://dergi.siirt.edu.tr/index.php/ziraat $\begin{aligned} & \text { Turk J Agric Res } \\ & \text { (2014) 1: 154-161 } \\ & \text { TÜTAD } \\ & \text { ISSN: 2148-2306 }\end{aligned}$

\title{
Tuz Stresinin Farklı Anaçlar Üzerine Aşılı Kirazın Vejetatif Gelişimine Etkilerinin Belirlenmesi
}

\author{
Cenk KÜÇÜKYUMUK ${ }^{1 *}$, Halit YILDIZ ${ }^{1}$, Ali ÜNLÜKARA ${ }^{2}$ \\ ${ }^{l}$ Meyvecilik Araşttrma İstasyonu Müdürlüğ̈̈, Eğirdir-Isparta, TÜRKIYY \\ ${ }^{2}$ Erciyes Üniversitesi, Ziraat Fakültesi, Biyosistem Mühendisliği Bölümü, Kayseri, TÜRKiYE
}

Geliş Tarihi/Received: 21.08 .2014

Kabul Tarihi/Accepted: 12.09 .2014

*Sorumlu Yazar/Correspondence: cenkkucukyumuk@hotmail.com

Özet: Bu çalışmada, farklı tuz içeriğine sahip sulama sularının, 0900 Ziraat kiraz çeşidinin bazı vejetatif gelişim parametrelerine olan etkileri araştırılmıştır. Araştırma 2013 yılında Eğirdir Meyvecilik Araştırma İstasyonu Müdürlüğ̈̈’nde saksı çalışması olarak yürütülmüştür. Araştırmada, ülkemizde kiraz yetiştiriciliğinde en çok kullanılan anaçlar olan kuş kirazı (Prunus avium L.) ve mahlep (Prunus mahalep L.) anaçları üzerine așılı 1 yașındaki 0900 Ziraat kiraz çeșidi fidanları kullanılmıştır. Fidanlar 1:2:1:0.5 oranlarında kum+tınlı toprak+torf+çiftlik gübresi karışımını içeren 40’ar $\mathrm{kg}$ harcın bulunduğu 50 litre hacimli saksılara dikilmiștir. Araștırma konusu olarak, her çeșit/anaç kombinasyonu için 4 farklı tuz içeriğine sahip sulama suyu $\left(\mathrm{T}_{1}=0.3 \mathrm{dS} \mathrm{m}^{-1}, \mathrm{~T}_{2}=2.0 \mathrm{dS} \mathrm{m}^{-1}, \mathrm{~T}_{3}=4.0 \mathrm{dS} \mathrm{m}^{-1}\right.$ ve $\left.\mathrm{T}_{4}=6.0 \mathrm{dS} \mathrm{m}^{-1}\right)$ ele alınmıştır. Tuzlu su uygulamalarının fidanların gövde çapı, bitki boyu, sürgün uzunluğu ve sürgün çapına etkilerini belirlemek için tüm ölçümler yetişme dönemi boyunca 15 gün aralıklarla yapılmış ve dönemsel değişimler de belirlenmiştir. Araştırma sonucuna göre, tuz stresinin kiraz fidanlarının vejetatif gelişimini yavaşlattığı belirlenmiştir. Fidanların vejetatif gelişim sonuçları değerlendirildiğinde, kuş kirazı anaçlı (Prunus avium L.) fidanların sulama suyu tuzluluğuna mahlep anaçlı (Prunus mahalep L.) fidanlardan daha hassas olduğu belirlenmiştir. Tuz içeriği yüksek sulama suyuna sahip kiraz yetiştiriciliği yapılan bölgelerde anaç olarak mahlep anacının kullanılması önerilebilir bulunmuştur.

Anahtar Kelimeler: Tuzluluk, 0900 Ziraat, Prunus avium L., Prunus mahalep L., vejetatif gelişim

\section{Determining of the Effects of Salinity Stress on Vegetative Development of Sweet Cherry Grafted on Different Rootstocks}

\begin{abstract}
In this study, the effects of different levels of irrigation water salinity on vegetative development of 0900 Ziraat sweet cherry variety was investigated. The study was conducted at Eğirdir Fruit Research Station as pot experiment in 2013. One year old nurseries (0900 Ziraat variety) grafted on mazzard (Prunus avium L.) and mahalep (Prunus mahalep L.) rootstocks used commonly for sweet cherry growing in Turkey were used. A mixture $(40 \mathrm{~kg})$ of sand + loamy soil + peat + farm yard (1:2:1:0.5 ratios) was placed into 50 liter pots and one year old sweet cherry trees were planted in 50 litre pots. Four different levels of salinity water treatments $\left(T_{1}=0.3 \mathrm{dS} \mathrm{m}^{-1}, \mathrm{~T}_{2}=2.0 \mathrm{dS} \mathrm{m}^{-1}, \mathrm{~T}_{3}=4.0 \mathrm{dS} \mathrm{m}^{-1}\right.$ and $\left.\mathrm{T}_{4}=6 \mathrm{dS} \mathrm{m}^{-1}\right)$ were used for both variety/rootstocks combinations as research subjects. The all measurements were done for every 15 days during growing period for determining effects of salinity water treatments on trunk diameter, plant height, shoot length and shoot diameter and periodic alterations were also determined. According to the study, it was determined that vegetative development of sweet cherry trees was inhibited by salinity stress. According to results of vegetative development, it was found that nurseries grafted on mazzard rootstocks (Prunus avium L.) were more sensitive than nurseries grafted on mahalep rootstocks (Prunus mahalep L.). It can be that mahalep rootstock should be used for sweet cherry growing areas which has high irrigation water salinity.
\end{abstract}

Keywords: Salinity, 0900 Ziraat, Prunus avium L., Prunus mahalep L., vegetative development 


\section{Giriș}

Çevre kirliliği, aşırı sulama, gübreleme ve benzeri diğer faaliyetler su kaynaklarının kalitesini olumsuz etkilemektedir. Suyun oransal olarak en çok kullanıldığı tarımsal üretim de bu durumdan etkilenmektedir. Sulanan tarım alanlarında Türkiye ve dünyada en çok karşılaşılan "tuzluluk" sorunudur. Dünyada tuzluluk problemine sahip tarım alanlarının miktarı 9 milyon hektardan fazladır (Tuteja, 2007). Tarımsal alanlarda tuzluluğun artması, toprağın yapısını bozmakta, bitkilerin ürün kalitesi ve verimliliğini önemli ölçüde sınırlandırmaktadır (Yılmaz ve ark., 2011).

Tarımsal üretimde tuzlu suların kullanılma zorunluluğu, tuz stresinin bitki gelişimi üzerinde bilgi sahibi olunmasını gerektirir ve bu alanda yapılacak çalışmalara ihtiyaç bulunmaktadır. Tarımsal, evsel ve endüstriyel üretim alanlarında kullanılan su miktarının artması nedeniyle sulamada tuzlu suların kullanımı konusu giderek artan bir ilgiye sahip olan bir araştırma konusu olmuştur (Ünlükara ve ark., 2008).

Kiraz üretimi meyve yetiştiriciliğin önemli dallarından biridir. Dünya kiraz üretiminde 2012 yılı üretim verilerine göre Türkiye yıllık 480.748 ton kiraz üretimiyle birinci sırada yer almaktadır (Anonymous, 2014). Albenisi yüksek ve sağlik açısından faydalı bir meyve olan kiraz yetiştiriciliğinde son yıllarda su kaynaklarının miktarının azalması, su kalitesinin düşmesi vb. sorunlar sık karşılaşılan bir durumdur. Kiraz yetiştirilen alanlarda gelecekte düşük kaliteli su kaynaklarının kullanma zorunluluğu olabilir. Bu nedenle drenaj, atık, tuzlu vb. sulama sularıyla yapılacak sulamaların kiraz ağaçlarının gelişimi üzerindeki etkilerinin belirlenmesi gerekmektedir. Türkiye'de kiraz yetiştiriciliğinde farklı taç büyüklüklerine sahip bodur ve yarı bodur anaçlar kullanılmaya başlanılsa da, halen kuş kirazı (Prunus avium L.) ve mahlep (Prunus mahalep L.) anaçları yaygın olarak kullanılmaktadır (Eroğul, 2012).

$\mathrm{Bu}$ çalışmada, farklı tuz içeriğine sahip sulama sularının kuş kirazı (Prunus avium L.) ve mahlep (Prunus mahalep L.) anaçları üzerine aş11 0900 Ziraat kiraz çeşidinin bazı vejetatif gelişim parametrelerine olan etkileri incelenmiştir.

\section{Materyal ve Yöntem}

\subsection{Materyal}

Araştırma, Eğirdir Meyvecilik Araştırma İstasyonu Müdürlüğü’nde 2013 yılında sera koşullarında yürütülmüştür. Denemede, kuş kirazı (Prunus avium L.) ve mahlep (Prunus mahalep L.) anaçları üzerine aşılı 0900 Ziraat kiraz çeşidine ait bir yaşlı fidanlar bitkisel materyal olarak kullanılmıştır. Çalışmada, hacmi 50 litre olan saksılara (alt çap $=35 \mathrm{~cm}$, üst çap $=43 \mathrm{~cm}$, yükseklik= $42 \mathrm{~cm})$ doldurulan ve 1:2:1:0.5 oranlarındaki kum+tınlı toprak+torf+çiftlik gübresi karışımlarından oluşan harçlar yetiştirme ortamı olarak kullanılmıştır. Oluşturulan yetiştirme ortamına ait bazı fiziksel ve kimyasal özellikler Tablo 1'de verilmiştir.

Tablo 1. Deneme öncesi yetiştirme ortamının bazı fiziksel ve kimyasal özellikleri

\begin{tabular}{|c|c|}
\hline Özellik & Değeri \\
\hline Kum, \% & 34.2 \\
\hline Kil, \% & 35.3 \\
\hline Silt, \% & 30.5 \\
\hline Bünye sınıfi & Killi tınlı \\
\hline Tarla kapasitesi, \% & 24.1 \\
\hline Solma noktas1, \% & 11.1 \\
\hline Hacim ağırlı̆̆ $1, \mathrm{~g} \mathrm{~cm}^{-3}$ & 1.38 \\
\hline $\mathrm{EC}, \mathrm{dS} \mathrm{m}^{-1}$ & 0.630 \\
\hline $\mathrm{pH}$ & 7.18 \\
\hline Kireç, \% & 11.14 \\
\hline Organik madde, $\%$ & 6.3 \\
\hline Alınabilir fosfor, ppm & 170 \\
\hline Alınabilir potasyum, ppm & 294 \\
\hline Alınabilir kalsiyum, ppm & 1102 \\
\hline Alınabilir magnezyum, ppm & 1701 \\
\hline
\end{tabular}

Araştırmada kullanılan sulama suyu Eğirdir Meyvecilik Araştırma İstasyonu Müdürlüğü arazisinde bulunan sulama kuyusundan temin edilmiştir. Sulama suyu; ABD Tuzluluk Laboratuvarı Grafik Sistemine göre $\mathrm{C}_{2} \mathrm{~S}_{1}$ sinıfinda (tuzluluk: $0.310 \mathrm{dS} \mathrm{\textrm {m } ^ { - 1 }}$, SAR: 1.04) olup (Anonymous, 1954), sulama için elverişlidir.

\subsection{Yöntem}

Araştırma 3 tekerrürlü tesadüf parselleri deneme desenine göre kurulmuş ve her tekerrürde 3 adet fidan kullanılmıştır. Bitkisel materyaller saksılara Nisan ayında dikilmiştir. Araştırma konular1; $\mathrm{T}_{1}=$ Kontrol (kuyu suyu), $\mathrm{T}_{2}=2 \mathrm{dS} \mathrm{m}^{-1}$, $\mathrm{T}_{3}=4 \mathrm{dS} \mathrm{m}^{-1}$ ve $\mathrm{T}_{4}=6 \mathrm{dS} \mathrm{m}^{-1}$ olmak üzere 4 farklı tuzlu su uygulamasından oluşmaktadır. Kontrol konusunun elektriksel iletkenlik (EC) değeri 0.3 $\mathrm{dS} \mathrm{m} \mathrm{m}^{-1}$ olarak ölçülmüştür. Tuzlu su, Sodyum Adsorbsiyon Oranı (SAR) 5 olacak şekilde; kalsiyum klorit $\left(\mathrm{CaCl}_{2}\right)$, magnezyum sülfat $\left(\mathrm{MgSO}_{4}\right)$ ve sodyum klorit $(\mathrm{NaCl})$ tuzlarının kuyu suyuna $\left(\mathrm{T}_{1}\right)$ eklenmesiyle hazırlanmıştır. $\mathrm{Ca} / \mathrm{Mg}$ oranı $1 / 1$ meq $\mathrm{L}^{-1}$ olarak dikkate alınmıştır. Kontrol konusu olan suyun tuzluluk değerinde $\left(\mathrm{EC}_{\mathrm{w}}\right)$ sezon içerisinde değişim olup olmadığını belirlemek için belli dönemlerde ölçüm yapılmıştır.

Sulama suyu ihtiyacı Ünlükara ve ark. (2010) tarafından bildirildiği şekilde belirlenmiştir. Saksı 
içindeki harcın tarla kapasitesi değerini hesaplamak için; deneme başlangıcında içinde bitki olmayan 5 adet saksıdaki harç karışımı su ile doyurulmuş, sızma olunca evaporasyonu önlemek için üstleri alüminyum folyo ile kaplanmıştır. 48 saat sonra saksılar tartılmış ve ortalama değerler tarla kapasitesi $\left(W_{F C}\right)$ olarak dikkate alınmıştır. Her sulamadan önce tüm saksılar tartılmış $(W)$, su ihtiyacı belirlenmiştir. Buna göre, her sulamada uygulanan su miktarı Eşitlik (1)'e göre hesaplanmıştır. Yıkama suyu olarak, her sulamada ihtiyacı olan su miktarı üzerine \% 20 oranında sulama suyu eklenmiş ve sulama yapılmıştır. Her sulamadan sonra sızan suyu tartmak amaciyla her saksıda altlık kullanılmıştır.

$$
I=\left(W_{F C}-W\right) /(1-L F)
$$

$\mathrm{Bu}$ eşitlikte; $W_{F C}$, saksılara ait tarla kapasitesi (g); $W$, her sulamadan önce ölçülen saksı ağırlığı (g); $L F$, sızma faktörü (sızan su/uygulanan su)'dür.

Araştırmada, sulama aralığı 5 gün olarak dikkate alınmış olup, Mayıs ayı başından itibaren programlı olarak sulamalara başlanmış, eylül ayının ilk haftasında da sulamalara son verilmiştir.

Deneme sonunda fidanlar söküldükten sonra, her saksıdan homojen olacak biçimde bitki kök bölgesi çevresinden toprak örnekleri alınmış ve saturasyon çamurunda Richards (1964)'a göre toprak tuzluluğu belirlenmiştir.

Farklı tuzlu su düzeylerinin fidanların vejetatif gelişimine etkilerini belirlemek amacıyla; her tekerrürden seçilen bir adet fidanda, dikimde ve mayıs ayından itibaren 15 gün aralıklarla ölçümler yapılmıştır. Buna göre; gövde çap1, aş1 noktasından $15 \mathrm{~cm}$ yukarıda kuzey-güney ve doğubatı yönlerinde dijital kumpas ile; bitki boyu, aş1 noktasından fidanın en üst noktasına kadar olan mesafe şeritmetre ile; sürgün çap1, tüm sürgünlerin gövdeye bağlandığ yerden itibaren $5 \mathrm{~cm}$ mesafede dijital kumpas ile; sürgün uzunluğu ise, tüm sürgünlerin gövdeye bağlandığı yerden sürgün ucuna kadar olan mesafe ölçülerek bulunmuştur.

Araştırmadan elde edilen veriler JUMP istatistik paket programında varyans analizine tabi tutulmuş, uygulamalar arasındaki farklılıklar LSD (Least Significant Difference) testi ile değerlendirilmiştir.

\section{Bulgular ve Tartışma}

\subsection{Bitki su tüketimi ve toprak tuzluluğu}

Sulama suyunun tuz seviyesine göre konular arasında farklılık olmuş, tuz içeriği arttıkça bitki su tüketimi değerlerinde azalma olduğu belirlenmiştir (Tablo 2). Tuz içeriğinin artması su tüketimini olumsuz etkilemiştir. 0900 Ziraat/kuş kirazı fidanlarında kontrol konusu olan $\mathrm{T}_{1}$ konusunda su tüketimi 64.90 litre iken, tuzluluk seviyesi en yüksek olan $\mathrm{T}_{4}$ konusunda 31.20 litre olmuştur. Yine 0900/mahlep fidanlarında kontrol konusunda su tüketimi 84.70 litre iken, $\mathrm{T}_{4}$ konusunda 40.70 litre olarak belirlenmiştir. Murkute ve ark. (2005) Sour portakal ve Kleopatra mandarin meyvelerinde, Can (2007) satsuma mandarininde sulama suyu tuz içeriğinin artmasıyla bitki su tüketiminin etkilendiğini ve azaldığını tespit etmişlerdir. Yılmaz ve ark. (2011) da, tuz içeriği yüksek suların bitkilerin su tüketimini azalttığını bildirmektedirler.

Tablo 2. Konulara göre bitki su tüketimi miktarları

\begin{tabular}{ccc}
\hline \multirow{2}{*}{ Konular } & \multicolumn{2}{c}{ Bitki su tüketimi (ET), L } \\
\cline { 2 - 3 } & 0900 Ziraat/Kuş kirazı & 0900 Ziraat/Mahlep \\
\hline $\mathrm{T}_{1}$ & 64.90 & 84.70 \\
$\mathrm{~T}_{2}$ & 50.45 & 62.50 \\
$\mathrm{~T}_{3}$ & 40.20 & 46.40 \\
$\mathrm{~T}_{4}$ & 31.20 & 40.70 \\
\hline
\end{tabular}

ET: Evapotranspirasyon, L: Litre

Tablo 3'te toprak tuzluluğu ölçüm sonuçları verilmiştir. Kontrol konusu hariç diğer konularda, 0900 Ziraat/mahlep fidanlarına ait toprak tuzluluğu değerleri daha yüksek çıkmıştır. Bunun nedeni 0900 Ziraat/mahlep fidanlarının bitki su tüketiminin daha yüksek olması nedeniyle toprakta biriken tuz miktarının daha yüksek olması olabilir. Öte yandan; yapılan birçok araştırmalarda (Hoffman ve ark., 1971; James ve ark., 1982; Üzen, 2009), araştırıcılar, yüksek tuzluluk düzeyine sahip sulamalarda su tüketiminin azalması olayını, sulama suyu tuzluluğuyla ilişkilendirmişlerdir. Shalhevet (1994) ve Tekin (2011), buharlaşma miktarının tuzluluktan etkilendiği sürece, oransal verim ve bitki su tüketiminde değişmeler görüleceğini ifade etmişlerdir. Benzer şekilde, Smets ve ark. (1997), sulama suyu niteliğinin bitkideki oransal terlemeyi etkilediğini, sulama suyu elektriksel iletkenliğinin $1 \mathrm{dS} \mathrm{m}^{-1}$ den $4 \mathrm{dS} \mathrm{m}^{-1}$ ye çıkarılması durumunda, terlemenin $\% 8$ düzeyinde azaldığını; bu durumun, kimi sulama yöntemlerinde \% 38 'e kadar yükseldiğini belirlemişlerdir. Sunulan çalışmada, elde edilen sonuçlar, yukarıda özetlenen sonuçları doğrular niteliktedir.

Tablo 3. Farklı tuz içeriğine sahip suların topraktaki tuz birikimine etkileri $\left(\mathrm{dS} \mathrm{m}^{-1}\right)$

\begin{tabular}{ccc}
\hline Konular & 0900 Ziraat/Kuş kiraz1 & 0900 Ziraat/Mahlep \\
\hline $\mathrm{T}_{1}$ & $1.94 \mathrm{~d}^{* *}$ & $1.61 \mathrm{c}^{* *}$ \\
$\mathrm{~T}_{2}$ & $6.37 \mathrm{c}$ & $8.89 \mathrm{~b}$ \\
$\mathrm{~T}_{3}$ & $9.96 \mathrm{~b}$ & $13.94 \mathrm{a}$ \\
$\mathrm{T}_{4}$ & $13.44 \mathrm{a}$ & $16.58 \mathrm{a}$ \\
\hline ': Aynı sütunda aynı harfle gösterilen ortalamalar arasındaki farklılık \\
istatistiki açıdan önemsizdir, ${ }^{* *}: \mathrm{p}<0.01$ seviyesinde önemli
\end{tabular}




\subsection{Vejetatif gelişim}

\subsubsection{Gövde çapı}

Dikimdeki gövde çap1 değerlerinde yapılan istatistik analiz sonucuna göre değerler arasındaki farklılık önemsiz bulunmuştur. Bu sonuç, deneme kurulması aşamasında gelişimleri birbirine yakın özellikte fidanlar seçildiğini gösterir. Her iki farklı anaç için tuzlu su uygulamalarının etkisi istatistiksel olarak $\mathrm{p}<0.01$ seviyesinde önemli bulunmuştur. Kuş kirazı anaçlı fidanlarda istatistiksel olarak 3 farklı grup oluşmuş, $T_{3}$ ve $T_{4}$ konuları aynı grupta yer almıştır. Mahlep anaçlı fidanlarda ise, istatistiksel olarak iki farklı grup ortaya çıkmış, $\mathrm{p}<0.01$ seviyesindeki bu farklılık $\mathrm{T}_{1}$ ve $T_{2}$ konuları ile $T_{3}$ ve $T_{4}$ konuları arasında belirlenmiştir. $T_{3}$ ve $T_{4}$ konuları her iki anaç için de gövde çapı bakımından en düşük değerlerin yer aldığ 1 konular olmuştur (Tablo 4). Bu durumda, 4 $\mathrm{dS} \mathrm{m}^{-1}$ ve üzeri tuz içeriğine sahip sulama sularının kuş kirazı ve mahlep anaçlı kiraz fidanlarının gövde çap1 gelişimi üzerine benzer etkiye sahip olduğu söylenebilir.

Tablo 4. Dikimde ve gelişme dönemi sonunda fidanlara ait gövde çapı değerleri

\begin{tabular}{|c|c|c|c|}
\hline \multirow{2}{*}{ Konular } & \multicolumn{3}{|c|}{ Gövde çap1 (mm) } \\
\hline & 12 Nisan & 29 Ağustos & Artış (\%) \\
\hline & \multicolumn{3}{|c|}{0900 Ziraat/Kuş kirazı ${ }^{1}$} \\
\hline $\mathrm{T}_{1}$ & 12.50 & $15.20 \mathrm{a}^{* *}$ & 21.6 \\
\hline $\mathrm{T}_{2}$ & 12.08 & $13.85 \mathrm{~b}$ & 14.7 \\
\hline $\mathrm{T}_{3}$ & 11.86 & $12.80 \mathrm{c}$ & 8.0 \\
\hline \multirow[t]{2}{*}{$\mathrm{T}_{4}$} & 11.45 & $12.30 \mathrm{c}$ & 7.4 \\
\hline & \multicolumn{3}{|c|}{0900 Ziraat/Mahlep $^{1}$} \\
\hline $\mathrm{T}_{1}$ & 15.60 & $19.80 \mathrm{a}^{* *}$ & 26.9 \\
\hline $\mathrm{T}_{2}$ & 15.40 & $18.40 \mathrm{a}$ & 19.5 \\
\hline $\mathrm{T}_{3}$ & 15.19 & $16.55 \mathrm{~b}$ & 9.0 \\
\hline $\mathrm{T}_{4}$ & 14.49 & $15.70 \mathrm{~b}$ & 8.4 \\
\hline
\end{tabular}

Sökümdeki gövde çap1 sonuçlarına göre sulama suyunun tuz içeriği arttıkça gövde çapı gelişimi azalmıştır. En yüksek artış oranı $\mathrm{T}_{1}$ konusunda \% 21.6 ve \% 26.9 ile sirasiyla 0900 Ziraat/kuş kirazı ve 0900 Ziraat/mahlep fidanlarından elde edilmiştir (Tablo 4). Aynı tuz içeriğine sahip konular arasındaki artış oranları dikkate alındığında, mahlep anaçlı fidanların gövde çapı artışının daha yüksek olduğu belirlenmiştir.

Fidanların gövde çap1 gelişimi dönemsel olarak Şekil 1 ve 2'de gösterilmiştir. Buna göre her iki anaçlı fidanlar içinde $T_{3}$ ve $T_{4}$ konularında temmuz ayından itibaren gövde çapı gelişiminde azalma olmuştur. Kontrol konusunda $\left(\mathrm{T}_{1}\right)$ gelişim daha hızlı devam ederken, $2 \mathrm{dS} \mathrm{m}^{-1}$ tuz içeriğine sahip sulama suyuyla sulanan fidanların kontrol konusuna yakın bir gelişme izlediği tespit edilmiştir. Tuz içeriği yüksek sularla yapılan sulamalar sonucu toprakta tuz birikimi daha fazla olmuştur. $\mathrm{T}_{3}$ ve $\mathrm{T}_{4}$ konularında temmuz ayından itibaren toprakta biriken tuz etkisini göstermiş olabilir. Ashraf ve ark. (2004, 2007), tuzlulukvejetatif gelişim arasındaki ilişkiyi incelemek için yaptıkları çalışmalarda, kök bölgesinde tuzluluğun artmasıyla bitkinin kök ve sürgünlerindeki azot içeriğinin ve toplam kuru madde üretiminin azaldığını saptamışlardır. Yukarıda özetlenen araştırma sonuçlarının ışığında, sunulan çalışmada, yüksek tuzluluk ve yetersiz sulama koşullarının bitkinin besin ve su alımını engellediği; bunu sonunda bitkilerde çap gelişimleri, kök gelişimleri ve vejetatif gelişimlerine olumsuz etki yaptığı belirtilebilir.

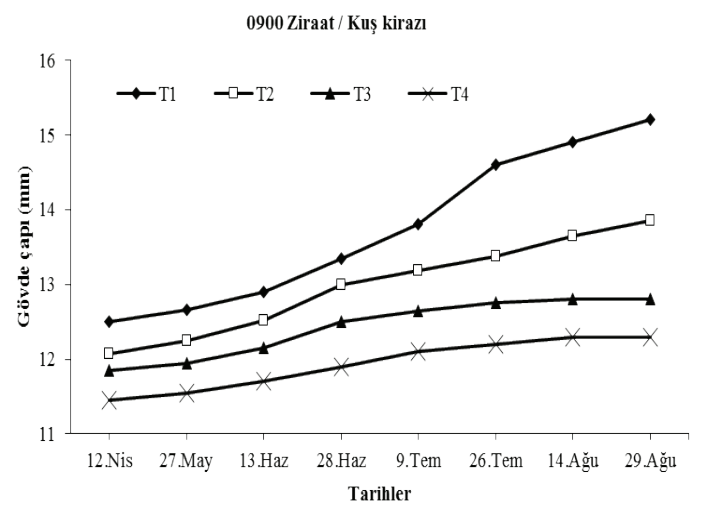

Şekil 1. Gelişme dönemi başlangıcından itibaren gövde çapının dönemsel değişimi (0900 Ziraat/Kuş kiraz1)

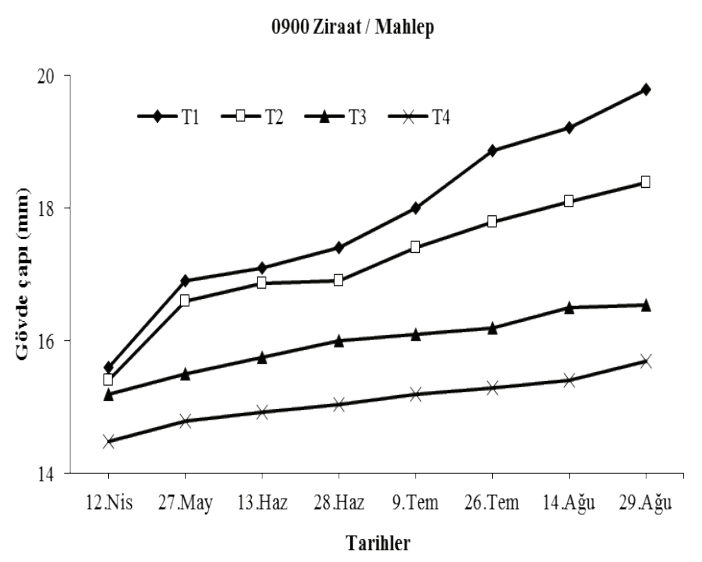

Şekil 2. Gelişme dönemi başlangıcından itibaren gövde çapının dönemsel değişimi (0900 Ziraat/Mahlep)

\subsubsection{Bitki boyu}

Fidanlara ait bitki boyu ölçüm sonuçları Tablo 5'te verilmiştir. Deneme sonundaki bitki boyu değerleri bakımından; kuş kirazı anacı üzerine aşılı kiraz fidanlarında tuzlu su uygulamalarının etkisi 
istatistiksel olarak $\mathrm{p}<0.05$ seviyesinde önemli bulunurken, mahlep anacı üzerine aşılı kirazlarda $\mathrm{p}<0.01$ seviyesinde önemlilik tespit edilmiştir. Her iki anaç üzerine aşılı fidanların bitki boylarının, sulama suyundaki tuz içeriğinin artışına paralel olarak azaldığı görülmektedir. Buna göre; kuş kirazı üzerine aşılı fidanlarda en yüksek bitki boyu değeri $(126.10 \mathrm{~cm}) \mathrm{T}_{1}$ konusunda elde edilmiştir. Mahlep anacı üzerine aşılı fidanlarda da en yüksek bitki boyu değeri $162.40 \mathrm{~cm}$ ile yine $\mathrm{T}_{1}$ konusunda belirlenmiştir. Gövde çap1 ölçümlerine benzer şekilde, bitki boyları bakımından da kuş kirazı ve mahlep anaçlı fidanlarda $T_{3}$ ve $T_{4}$ konuları istatistiksel olarak aynı gruplarda yer almışlardır (Tablo 5).

Tablo 5. Dikimde ve gelişme dönemi sonunda bitki boyu değerleri

\begin{tabular}{cccc}
\hline \multirow{2}{*}{ Konular } & \multicolumn{3}{c}{ Bitki boyu $(\mathrm{cm})$} \\
\cline { 2 - 4 } & \multicolumn{4}{c}{ 12 Nisan } & 29 Ağustos & Artış (\%) \\
\hline $\mathrm{T}_{1}$ & 97.60 & $126.10 \mathrm{a} \mathrm{a}^{*}$ & 29.2 \\
$\mathrm{~T}_{2}$ & 96.33 & $119.00 \mathrm{ab}$ & 23.5 \\
$\mathrm{~T}_{3}$ & 95.50 & $114.00 \mathrm{~b}$ & 19.4 \\
$\mathrm{~T}_{4}$ & 96.00 & $111.00 \mathrm{~b}$ & 15.6 \\
\hline \multicolumn{4}{c}{0900 Ziraat/Mahlep } \\
\hline $\mathrm{T}_{1}$ & 117.67 & $162.40 \mathrm{a}$ ** & 38.0 \\
$\mathrm{~T}_{2}$ & 118.67 & $152.10 \mathrm{~b}$ & 28.2 \\
$\mathrm{~T}_{3}$ & 119.00 & $139.10 \mathrm{c}$ & 16.9 \\
$\mathrm{~T}_{4}$ & 116.00 & $134.00 \mathrm{c}$ & 15.5 \\
\hline 1: Aynı sütunda aynı harfle gösterilen ortalamalar arasındaki farkl11k \\
istatistiki açidan önemsizdir, *: $\mathrm{p}<0.05$ seviyesinde önemli, **: $\mathrm{p}<0.01$ \\
seviyesinde önemli
\end{tabular}

Diğer yandan, deneme sonundaki bitki boyu değerlerinin dikim zamanına göre artışı genel olarak mahlep anaçlı fidanlarda daha yüksek olarak bulunmuştur. Bu artışlar, \% 38.0 ve \% 29.2 ile her iki anaç üzerine aşılı fidanların $T_{1}$ konusunda ölçülmüştür. En düşük artış oranları ise birbirine yakın gerçekleşmiş, kuş kirazı ve mahlep anaçlı fidanlar için bu değerler sırasıyla \% 15.6 ve \% 15.5 olarak belirlenmiştir (Tablo 5).

Dönemsel bitki boyu gelişimi incelendiğinde (Şekil 3 ve 4), her iki anaç için de temmuz ayından itibaren $T_{3}$ ve $T_{4}$ konularında yer alan fidanların bitki boyu gelişimi yavaşlamıştır. $T_{1}$ ve $T_{2}$ konularındaki fidanların gelişimi ise genel itibariyle birbirine yakın olmuştur. Sharma (1980) ve Tekin (2011) artan tuz derişiminin transpirasyondaki azalmalar nedeni ile bitki boyunu kısalttığını bildirmişlerdir. Ashraf ve ark. (2004), yaptığ çalışmada tuz derişiminin bitki boyunu \% 13.0-\% 36.5 arasında değişen oranlarda azalttığını açıklamışlardır. Ayrıca, Sivritepe ve Eriş (1996) ve Hussain ve ark. (1997), tuzun büyümeyi engellediğini, bitki gelişimini azalttığını ve hatta yüksek doz uygulamalarında (özellikle eşik değeri üzerindeki tuzluluklarda) bitki ölümlerine neden olduğunu saptamışlardır. Sunulan çalışmada benzer bulgular elde edilmiştir. Artan tuzluluk bitki gelişimini olumsuz yönde etkilemiştir.

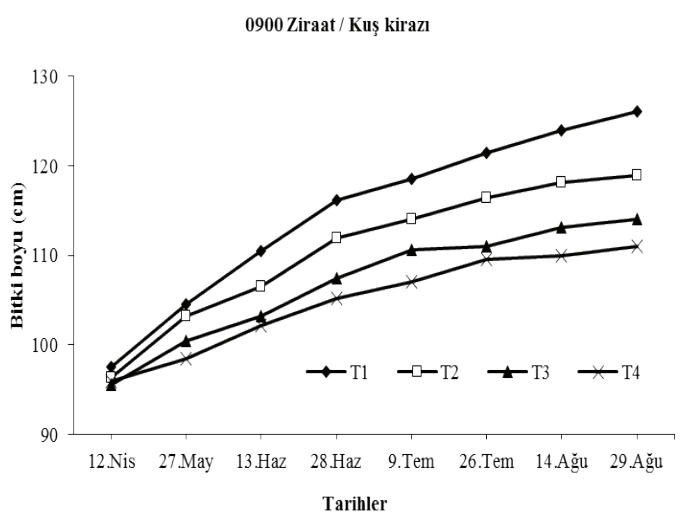

Şekil 3. Gelişme dönemi başlangıcından itibaren bitki boyundaki dönemsel değişimler (0900 Ziraat/Kuş kirazı)

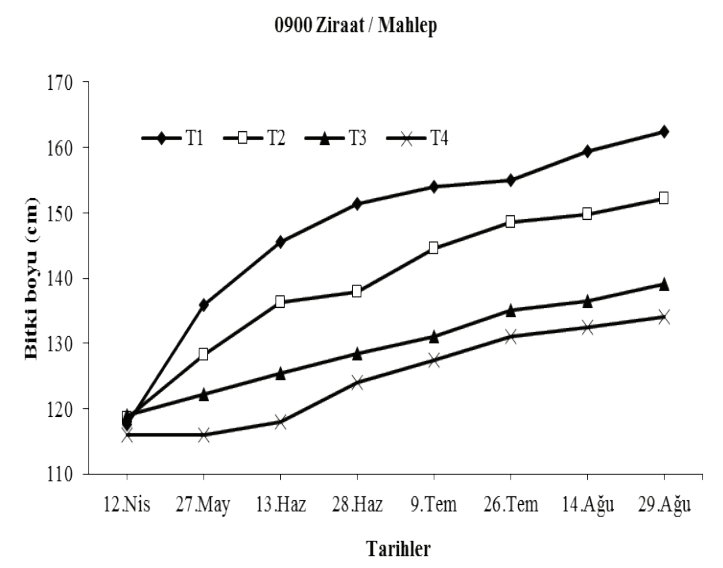

Şekil 4. Gelişme dönemi başlangıcından itibaren bitki boyundaki dönemsel değişimler $\quad(0900$ Ziraat/Mahlep)

\subsubsection{Sürgün çapı ve uzunluğu}

Gelişme dönemi başında (27 Mayıs) yapılan sürgün çapı ölçümleri arasında istatistiksel olarak fark bulunmamıştır. $\mathrm{Bu}$ durum erken gelişme dönemine kadar tuzlu su uygulamalarının sürgün çapı gelişimi üzerinde olumsuz etki yapmadığını gösterir. Gelişme döneminin sonunda ise, tuzlu su uygulamalarının her iki anaca aşılı fidanlarda sürgün çap1 üzerine istatistiksel olarak $\mathrm{p}<0.05$ seviyesinde önemli etkisi olmuştur. Her iki anaca aşılı kiraz fidanlarında sürgün çapının sulama suyundaki tuzluluğun artışına paralel olarak azaldığı görülmektedir. Gelişme dönemi sonundaki sürgün çap1 değerlerindeki artış incelendiğinde, kuș kirazı anaçlı fidanların gelișimi daha fazla olmuştur. En yüksek artış oranı \% 77.8 ile kuş 
kirazı anaçlı fidanlardan, \% 28.6 ile en düşük artış oranı da mahlep anaçlı fidanlardan elde edilmiştir (Tablo 6).

Tablo 6. Tuz stresi altındaki fidanların sürgün çapı değerleri

\begin{tabular}{|c|c|c|c|}
\hline \multirow[b]{2}{*}{ Konular } & \multicolumn{3}{|c|}{ Sürgün çap1 (mm) } \\
\hline & $\begin{array}{c}27 \text { Mayıs } \\
\text { (ilk ölçüm tarihi) }\end{array}$ & 29 Ağustos & Artış (\%) \\
\hline & \multicolumn{3}{|c|}{0900 Ziraat/Kuş kiraz1 $^{1}$} \\
\hline $\mathrm{T}_{1}$ & 3.66 & $6.50 \mathrm{a}^{*}$ & 77.8 \\
\hline $\mathrm{T}_{2}$ & 3.67 & $5.90 \mathrm{ab}$ & 60.9 \\
\hline $\mathrm{T}_{3}$ & 3.70 & $5.30 \mathrm{bc}$ & 43.2 \\
\hline $\mathrm{T}_{4}$ & 3.65 & $4.90 \mathrm{c}$ & 34.2 \\
\hline & \multicolumn{3}{|c|}{0900 Ziraat/Mahlep $^{1}$} \\
\hline $\mathrm{T}_{1}$ & 3.66 & $5.90 \mathrm{a}^{*}$ & 61.2 \\
\hline $\mathrm{T}_{2}$ & 3.50 & $5.40 \mathrm{ab}$ & 54.3 \\
\hline $\mathrm{T}_{3}$ & 3.49 & $5.10 \mathrm{ab}$ & 46.0 \\
\hline $\mathrm{T}_{4}$ & 3.50 & $4.50 \mathrm{~b}$ & 28.6 \\
\hline
\end{tabular}

Şekil 5 ve 6'da dönemsel sürgün çapı gelişimi gösterilmiştir.

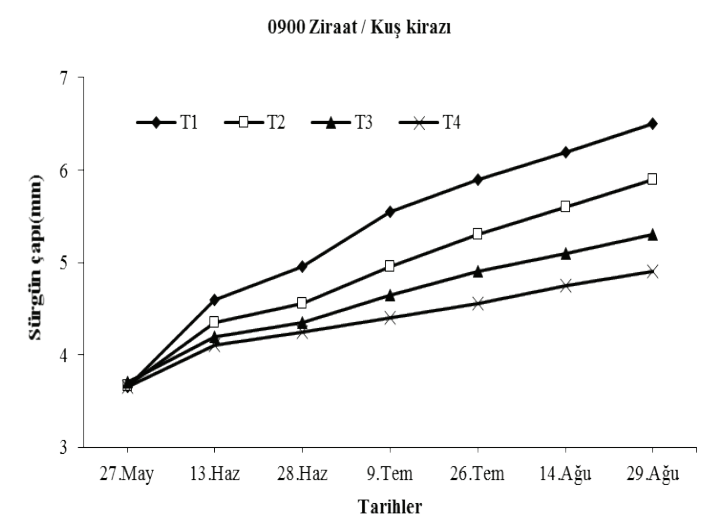

Şekil 5. Gelişme dönemi süresince sürgün çapının dönemsel değişimi (0900 Ziraat/Kuş kirazı)

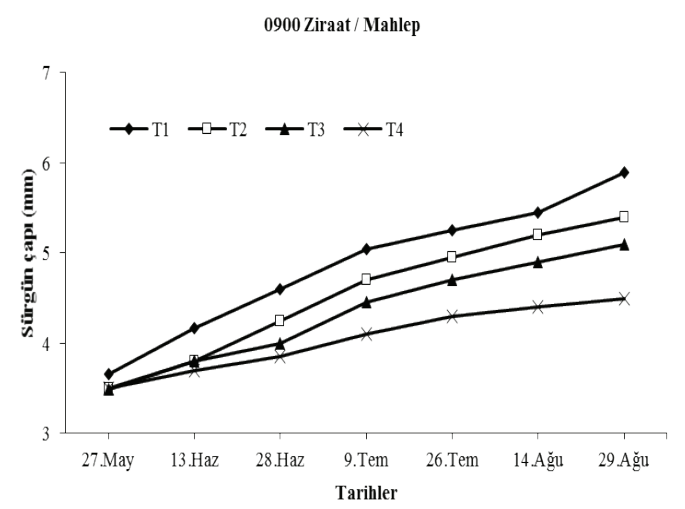

Şekil 6. Gelişme dönemi süresince sürgün çapının dönemsel değişimi (0900 Ziraat/Mahlep)
Kuş kirazı anaçlı fidanlarda $T_{3}$ ve $T_{4}$ konularındaki fidanlarda sürgün çapının dönemsel gelişimi, mahlep anaçlı fidanlarda ise $T_{2}$ ve $T_{3}$ konularındaki fidanların sürgün çapının dönemsel gelişimleri birbirine yakın olmuştur.

Kuş kirazı ve mahlep anaçlı fídanlara ait sürgün uzunluğu değerleri üzerine tuzlu su uygulamalarının etkileri istatistiksel olarak önemli bulunmuştur $(\mathrm{p}<0.01)$. Her iki anaca aşılı kiraz fidanlarında en yüksek sürgün uzunluğu $28.40 \mathrm{~cm}$ ve $43.40 \mathrm{~cm}$ ile $T_{1}$ konusunda ölçülmüştür. Kuş kirazı anaçlı fidanlarda $T_{2}$ ve $T_{3}$ konuları istatistiki olarak aynı grupta yer alırken, en düşük değerler her iki anaca aşılı fidanlarda da $\mathrm{T}_{4}$ uygulamasında tespit edilmiştir. Gelişme döneminin sonundaki artış oranlarına göre, mahlep anaçlı fidanlarda sürgün uzunluğu gelişimi kuş kirazı anaçlı fidanlara göre daha fazla olmuştur. En yüksek artış oranı \% 139.6 ile mahlep anaçlı fidanlardan, en düşük artış oranı ise \% 50.8 ile kuş kirazı anaçlı fidanlardan elde edilmiştir (Tablo 7). Artış oranlarına göre tuz içeriği yüksek sularla sulama yapıldığında bile sürgün uzunluğunun gelişiminin denemede yer alan diğer parametrelere göre daha hızlı olarak devam ettiği belirlenmiştir.

Tablo 7. Tuz stresi altındaki fidanların sürgün uzunluğu değerleri

\begin{tabular}{|c|c|c|c|}
\hline \multirow[b]{2}{*}{ Konular } & \multicolumn{3}{|c|}{ Sürgün uzunluğu $(\mathrm{cm})$} \\
\hline & $\begin{array}{c}27 \text { Mayis } \\
\text { (ilk ölçüm tarihi) }\end{array}$ & 29 Ağustos & Artış (\%) \\
\hline & \multicolumn{3}{|c|}{ 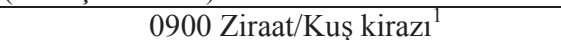 } \\
\hline $\mathrm{T}_{1}$ & 13.00 & $28.40 \mathrm{a}^{* *}$ & 118.5 \\
\hline $\mathrm{T}_{2}$ & 12.50 & $24.50 \mathrm{~b}$ & 96.0 \\
\hline $\mathrm{T}_{3}$ & 13.10 & $23.20 \mathrm{~b}$ & 77.1 \\
\hline $\mathrm{T}_{4}$ & 12.60 & $19.00 \mathrm{c}$ & 50.8 \\
\hline & \multicolumn{3}{|c|}{0900 Ziraat/Mahlep $^{1}$} \\
\hline $\mathrm{T}_{1}$ & 18.11 & $43.40 \mathrm{a}^{* *}$ & 139.6 \\
\hline $\mathrm{T}_{2}$ & 18.00 & $38.00 \mathrm{~b}$ & 111.1 \\
\hline $\mathrm{T}_{3}$ & 18.15 & $33.40 \mathrm{c}$ & 84.0 \\
\hline $\mathrm{T}_{4}$ & 18.20 & $29.20 \mathrm{~d}$ & 60.4 \\
\hline
\end{tabular}

Sürgün uzunluğu değerlerinin dönemsel değişimine göre, kuş kirazı anaçlı fidanlarda $T_{2}$ ve $\mathrm{T}_{3}$ konularında yer alan fidanlar birbirine yakın bir gelişme göstermiştir. $T_{2}$ ve $T_{3}$ konularında yer alan mahlep anaçlı fidanlarda gelişme döneminin ilk zamanlarında (mayıs-haziran) sürgün uzunluğu gelişimi birbirine yakın olmuştur. Kuş kirazı anaçlı fidanlarda $\mathrm{T}_{4}$ konusu, mahlep anaçlı fidanlarda ise $T_{3}$ ve $T_{4}$ konularında yer alan fidanların sürgün uzunluğu gelişimi temmuz ayından itibaren daha yavaş gerçekleşmiştir (Şekil 7 ve 8).

Vejetatif gelişim parametreleri genel olarak değerlendirildiğinde, sulama suyunun tuz içeriğinin artmasıyla birlikte bitki gelişiminin 
olumsuz etkilendiği ve yavaşladığ Dönemsel ölçümlere göre kiraz ağaçlarının gelişme sezonu ortasından (Temmuz ayı) itibaren kontrol konusu $\left(\mathrm{T}_{1}\right)$ hariç diğer konulara ait fidanlarda artan tuzluluğun bitki vejetatif gelişimini yavaşlatan etkisinin daha net görüldüğü belirlenmiştir. Bunun, artan tuz miktarı nedeniyle toprak suyunun kullanılabilirliğinin azalmasından ve bağlı olarak bitki gelişmesinin olumsuz etkilenmesinden ileri geldiği düşünülebilir. Benzer sonuçlar, kimi araştırmacılar (Tanji, 1990; Tekin, 2011) tarafindan da rapor edilmiştir. Bernstein (1980), farklı türdeki meyve ağaçlarında; Khanouja ve ark. (1980), üzümde; Akça ve Samsunlu (2012) ise, cevizde sulama suyunda çözünebilir tuz miktarının artmasıyla vejetatif gelişimin olumsuz etkilendiğini rapor etmişlerdir.

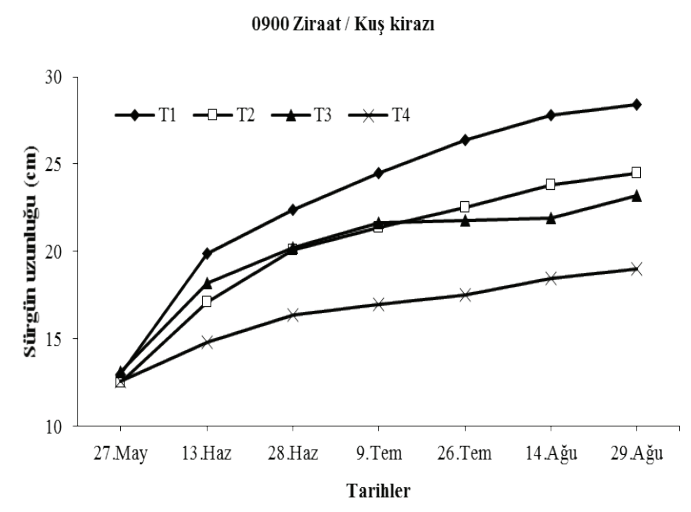

Şekil 7. Gelişme dönemi süresince sürgün uzunluğunun dönemsel değişimi (0900 Ziraat/Kuş kirazı)

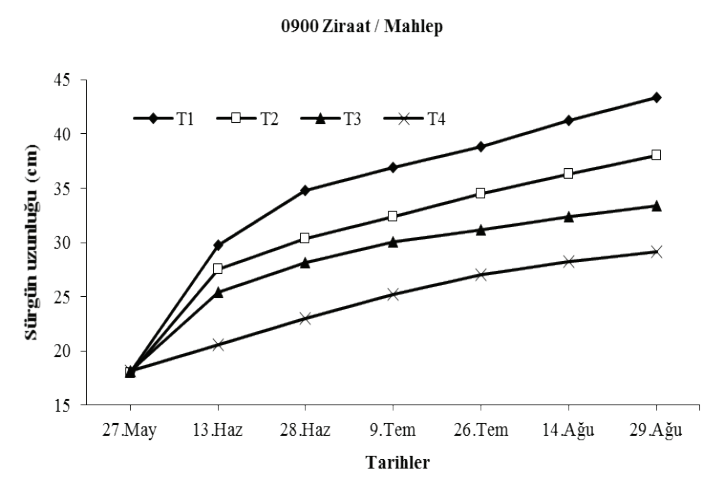

Şekil 8. Gelişme dönemi süresince sürgün uzunluğunun dönemsel değişimi (0900 Ziraat/Mahlep)

Farklı bitki türlerinde yapılan çalışmalarda da tuz içeriği yüksek sularla yapılan sulamaların bitki boyu başta olmak üzere vejetatif gelişim parametreleri üzerinde olumsuz etkilerinin olduğu ve gelişimi azalttığ 1 bildirilmiştir (Yurtseven ve ark., 1996; Mohammad ve ark., 1998; Ünlükara ve ark., 2008; Cemek ve ark., 2011). Sulama suyu tuzluluğunun artmasıla vejetatif gelişimin olumsuz etkilenmesi sonuçları bu çalışmalara benzerlik göstermektedir.

\section{Sonuçlar}

Çalışma sonunda, tuz içeriği yüksek sularla yapılan sulamalara karşı 0900 Ziraat/kuş kirazı fidanlarının 0900 Ziraat/mahlep fidanlarından daha hassas olduğu belirlenmiştir. Özellikle $\mathrm{T}_{3} \quad(4 \mathrm{dS}$ $\left.\mathrm{m}^{-1}\right)$ ve $\mathrm{T}_{4}\left(6 \mathrm{dS} \mathrm{m}^{-1}\right)$ sulama suyu tuzluluk seviyelerinin kiraz ağaçlarının vejetatif gelişimi üzerinde benzer etkilere sahip olduğu söylenebilir. Yetişme sezonu ortasından (Temmuz ayı) itibaren $\mathrm{T}_{3}$ ve $\mathrm{T}_{4}$ tuz içeriğine sahip sularla sulanan fidanların vejetatif gelişimi parametrelerinde olumsuz etkiler görülmeye başlanmıștır. Tuz içeriği yüksek sulama suyunun kullanılmasının zorunlu olduğu kiraz yetiştirilen alanlarda anaç olarak mahlep anacinın kullanılması kiraz üreticilerine önerilebilir.

\section{Kaynaklar}

Akça, Y., Samsunlu, E., 2012. The effect of salt stress on growth, chlorophyll content, proline and nutrient accumulation and $\mathrm{K} / \mathrm{Na}$ ratio in walnut. Pakistan Journal of Botany, 44(5): 1513-1520.

Anonymous, 1954. USSL, Diagnosis and Improvement of Saline and Alkalin Soils. Agricultural Handbook No. 60, US Goverment Printing Office, Washington.

Anonymous, 2014. FAO. http://faostat3.fao.org/faostatgateway/go/to/browse/Q/QC/E (Erişim tarihi: 15.08.2014).

Ashraf, M., Foolad, M.R., 2007. Improving plant abiotic-stress resistance by exogenous application of osmoprotectants glycine betaine and proline. Environmental Experience of Botany, 59: 206-216.

Ashraf, M., Mukhtar, N., Rehman, S., Rha, E.S., 2004. Salt-induced changes in photosynthetic activity and growth in a potential plant bishop's weed (Ammolei majus L.). Photosynthetica, 42: 543-550.

Bernstein, L., 1980. Salt Tolerance of Fruit Crops. United States Department of Agriculture, Agriculture Information Bulletin, Number 292, US Goverment Printing Office, Washington.

Can, O., 2007. Tuzlu koşullarda satsuma mandarini bitki su tüketiminin belirlenmesi üzerine bir araştırma. Yüksek lisans tezi, Ege Üniversitesi Fen Bilimleri Enstitüsü, İzmir.

Cemek, B., Ünlukara, A., Karaman, S., Gökalp, Z., 2011. Effects of evapotranspiration and soil salinity on some growth parameters and yield of lettuce (Lactuca saliva var. crispa) ZemdirbysteAgriculture, 98(2): 139-148.

Eroğul, D., 2012. Kiraz yetiştiriciliğinde anaçların kullanımı. Adnan Menderes Üniversitesi Ziraat Fakültesi Dergisi, 9(2): 19-24. 
Hoffman, G.J., Rawlings, S.L., Garber, M.J., Cullen, E.M., 1971. Water relations growth cotton as influenced by salinity and relative humidity. Agron. Jour., 63: 822-826.

Hussain, G., Al-Jaloud, A.A., Al-Shammary, S.A., Karimulla, S., Sal-Aswad, S.O., 1997. Effect of saline irrigation germination and growth garameterd of barley (Hordeum vulgare L.) in a pot experiment. Agricultural Water Management, 34: 125-135.

James, D.W., Hanks, R.J., Jurinak, J.J., 1982. Modern Irrigated Soils. John Wiley and Sons, New York.

Khanouja, S.D., Chaturvedi, K.N.J., Garg, V.K., 1980. Effect of exchangeable sodium percentage on the growth and mineral composition of "Thomson Seedless" grapevine. Scientia Horticulturae, 12(1): 47-53.

Mohammad, M., Shibli, R., Ajlouni, M., Nimri, L., 1998. Tomato root and shoot responses to salt stress under different levels of phosphorus nutrition. Journal of Plant Nutrition, 21(8): 1667-1680.

Murkute, A.A., Sharma, S., Singh, S.K., 2005. Citrus in terms of soil and water salinity: A review. Journal of Scientific and Industiral Research, 64: 393-402.

Richards, L.A., 1964. Diagnosis and Improvement of Saline and Alkali Soils. USDA Agriculture Handbook, No:6, Washington, D.C. USA.

Shalhevet, J., 1994. Using water of marginal quality for crop production: Major Issues. Agricultural Water Management, 25: 233-269.

Sharma, D.P., 1980. Effect of using salinity water to supplement canal water irrigation on the crop growth of rice. Curr. Agr. 4: 79-82.

Sivritepe, N., Eriş, A., 1996. Tuz stresi. Uludă Üniversitesi Ziraat Fakültesi Dergisi, 12: 209-222.
Smets, S.M.P., Kuper, M., Van Dam, J.C., Feddes, R.A., 1997. Salinization and crop transpiration of irrigated fields in Pakistan's Punjab. Agricultural Water Management, 35: 43-60.

Tanji, K.K., 1990. Agricultural Salinity Assesment and Management. American Society of Civil Engineers, New York.

Tekin, S., 2011. Tuzlu sulama sularının buğdayda verim ve kaliteye etkisi. Doktora tezi, Çukurova Üniversitesi Fen Bilimleri Enstitüsü, Adana.

Tuteja, N., 2007. Mechanisms of high salinity tolerance in plants. Methods in Enzymology, 428: 419-438.

Ünlükara, A., Kurunç, A., Kesmez, G.D., Yurtseven, E., 2008. Growth and evapotranspiration of okra (Abelmoschus esculentus L.) as influenced by salinity of irrigation water. Journal of Irrigation and Drainage, 134: 160-166.

Ünlükara, A., Kurunç, A., Kesmez, G.D., Yurtseven, E., Suarez, D.L., 2010. Effects of salinity on eggplant (Solanum melongena L.) growth and evapotranspiration. Journal of Irrigation and Drainage, 59: 203-214.

Üzen, N., 2009. Güneydoğu Anadolu Bölgesi koşullarında yetiştirilen kimi pamuk çeşitlerinin farklı seviyelerdeki tuz stresine gösterdikleri tepkilerin incelenmesi. Yüksek lisans tezi, Çukurova Üniversitesi Fen Bilimleri Enstitüsü, Adana.

Yılmaz, E., Tuna, A.L., Bürün, B., 2011. Bitkilerin tuz stresi etkilerine karşı geliştirdikleri tolerans stratejileri. Celal Bayar Üniversitesi Fen Bilimleri Dergisi, 7(1): 47-66.

Yurtseven, E., Öztürk, A., Kadayıfçı, A., Ayan, B., 1996. Sulama suyu tuzluluğunun biberde (Capsicum annиит) farklı gelişme dönemlerinde bazı verim parametrelerine etkisi. Ankara Üniversitesi Ziraat Fakültesi Tarım Bilimleri Dergisi, 2(2): 5-9. 